\title{
Spatial density-independent parasitism of the inquiline, Diomorus aiolomorphi (Hymenoptera: Torymidae), on the bamboo gall maker, Aiolomorphus rhopaloides (Hymenoptera: Eurytomidae)
}

\author{
Ei'ichi SHIBATA* \\ Laboratory of Forest Protection, Graduate School of Bioagricultural Sciences, Nagoya University; Nagoya 464-8601, Japan \\ (Received 15 February 2006; Accepted 5 May 2006)
}

\begin{abstract}
Diomorus aiolomorphi Kamijo (Hymenoptera: Torymidae) is an inquiline on bamboo galls formed by the bamboo gall maker Aiolomorphus rhopaloides Walker (Hymenoptera: Eurytomidae). I examined (1) the spatial and vertical distribution of galls and galls from which $D$. aiolomorphi emerged, and (2) the spatial density-dependent parasitism of D. aiolomorphi in a stand of Phyllostachys heterocycla. The percentages of galls from which $D$. aiolomorphi emerged tended to be higher than those from which $A$. rhopaloides emerged and ranged from $21.5 \%$ to $45.6 \%$. Bamboo galls and galls from which D. aiolomorphi emerged were distributed contagiously on bamboo culms and branches. The attack of $D$. aiolomorphi was not dependent on gall density on culms and branches. D. aiolomorphi is synovigenic; females have no eggs in their ovaries when they emerge but develop eggs continuously as adults age. Thus, D. aiolomorphi females cannot lay eggs on freshly initiated galls aggregatively and successively, suggesting that $D$. aiolomorphi attacks regardless of gall density.
\end{abstract}

Key words: Aiolomorphus rhopaloides; bamboo gall maker; density-independent parasitism; Diomorus aiolomorphi; inquiline

\section{INTRODUCTION}

The spatial patterns of parasitism by insect parasitoids are important for the dynamics of host-parasitoid interactions (Hassell et al., 1991). In gall insects, there are many studies on detection of the spatial density-dependent parasitism; the hackberry nipplegall maker Pachypsylla celtidismamma (Homoptera: Psyllidae) (Lill, 1998), the galling sawfly Euura amerinae (Hymenoptera: Tenthredinidae) on Salix pentandra (Roininen et al., 1996), and the cynipid gall-former Andricus quercuscalicis (Hymenoptera: Cynipidae) on Quercus cerris (Hails and Crawley, 1992).

Adults of Diomorus aiolomorphi Kamijo (Hymenoptera: Torymidae) oviposit on young bamboo galls developed on young branchlets by the bamboo gall maker, Aiolomorphus rhopaloides Walker (Hymenoptera: Eurytomidae) (Takahashi and
Mizuta, 1971). D. aiolomorphi is univoltine. This species is known to be an inquiline (Takahashi and Mizuta, 1971), that is, a phytophagous insect that cannot make its own galls but feeds on gall tissues induced by a gall maker (Askew, 1961). Although inquilines are very common to many gall makers, they have received very little attention (Sanver and Hawkins, 2000).

The bamboo gall maker, A. rhopaloides, causes galls on two species of bamboo, Phyllostachys heterocycla Matsumura and P. bambusoides Siebold and Zuccarini (Monocotyledoneae: Gramineae) in Japan (Takahashi and Mizuta, 1971; Kobayashi, 1994; Yukawa and Masuda, 1996). A. rhopaloides is also univoltine; adult females emerge from galls from mid-April to early May (Shibata, 2001; Shibata and Ito, 2005) and oviposit in the young buds of bamboo branchlets, which develop into unitary galls (length: 20-30 mm, width: 2-4 mm) (Taka-

* E-mail: shibatae@agr.nagoya-u.ac.jp

DOI: 10.1303/aez.2006.493 
hashi and Mizuta, 1971). Outbreaks of $A$. rhopaloides occur occasionally in stands of $P$. heterocycla in west Japan (Kobayashi, 1994).

It is known that bamboo galls are distributed contagiously both on bamboo culms and branches in a bamboo stand (Shibata, 2003, 2005). The attack pattern of $D$. aiolomorphi on bamboo galls is important in evaluating the regulation of $A$. rhopaloides population density. This study examines (1) the spatial and vertical distribution of galls and galls from which $D$. aiolomorphi emerged, and (2) the spatial density-dependent parasitism of $D$. aiolomorphi.

\section{MATERIALS AND METHODS}

Study stand. This study was conducted in an approx. $400-\mathrm{m}^{2}$ stand of $P$. heterocycla in Nagoya City, central Japan. This stand was by the road and had not been managed. The nearest bamboo stand was apart from $1.2 \mathrm{~km}$.

Methods. In late March 1999, 2000 and 2001, five to eight bamboo culms were cut at random just before A. rhopaloides and D. aiolomorphi emergence. Culm height and diameter at breast height (dbh) of each bamboo were measured. All branches were clipped from each culm after measuring the height of the base of each branch from the ground. After the branch lengths had been measured and the number of galls on each branch counted, the individual galls were collected and put in individual test tubes (diameter: $1 \mathrm{~cm}$, length: $7 \mathrm{~cm}$ ) kept outdoors at ambient temperatures. Emerged A. rhopaloides and D. aiolomorphi were counted every 2 or 3 days until mid-July.

Statistical analyses. Statistical analyses were performed using the SPSS computer program (Norussis, 1993). Differences in mean bamboo heights and mean dbh among 3 years were tested by one-way ANOVA with Tukey's HSD multiple comparison test. One-way ANOVA was used to detect significant differences in gall numbers per culm (transformed to $\log [x+0.5]$ according to Yamamura (1999)), and percentages (transformed to arcsine-root) of galls from which $A$. rhopaloides emerged (\%GM) and galls from which $D$. aiolomorphi emerged (\%INQ) among 3 years. Differences in gall number per $10-\mathrm{cm}$ branch length (transformed to $\log [x+0.5]$ ), and \%GM and \%INQ (both transformed to arcsine-root) in each year among height classes were tested by one-way ANOVA with Tukey's HSD multiple comparison test. One-way ANOVA was used to test significant differences in gall numbers (transformed to $\log [x+0.5]$ ), and the \%INQ (transformed to arcsine-root) among branch length classes. Coefficient of determination $\left(r^{2}\right)$ was applied to the relationships between numbers of galls and galls from which D. aiolomorphi emerged per culm. \%INQ (transformed to arcsine-root) between the number of galls per $10-\mathrm{cm}$ branch length in each year were tested by one-way ANOVA with Tukey's HSD multiple comparison test. The spatial distribution patterns of galls and galls from which $D$. aiolomorphi emerged on bamboo culms and branches were analyzed using Morisita's $I_{\delta}$ index (Morisita, 1959), with $\chi^{2}$-test to test the null hypothesis of randomness (Krebs, 1998).

\section{RESULTS}

\section{Culm height and dbh}

There were no significant differences in culm height and dbh among 3 years (height: $F=0.098$, $\mathrm{df}=2, p=0.907$; dbh: $F=0.729$, df $=2, p=0.498)$ (Table 1).

\section{Number of galls, \%GM and \%INQ}

There were no significant differences in the mean numbers of galls per culm, \%GM and \%INQ

Table 1. Number of culms examined, mean height and diameter at breast height (dbh) of culms and number of galls examined

\begin{tabular}{cccrr}
\hline Year & Number of culms & Height $(\mathrm{m})$ & dbh $(\mathrm{cm})$ & Number of galls \\
\hline 1999 & 5 & $7.2 \pm 1.0 \mathrm{a}$ & $4.5 \pm 0.9 \mathrm{a}$ & 3,952 \\
2000 & 8 & $7.4 \pm 0.8 \mathrm{a}$ & $5.2 \pm 1.3 \mathrm{a}$ & 943 \\
2001 & 6 & $7.2 \pm 0.4 \mathrm{a}$ & $5.0 \pm 0.7 \mathrm{a}$ & 1,430 \\
\hline
\end{tabular}

Mean \pm SD.

Same letters in each column indicate no significant differences $(p>0.05)$. 
Table 2. Mean number of galls, mean percentage of galls from which A. rhopaloides emerged and of galls from which D. aiolomorphi emerged

\begin{tabular}{cccc}
\hline Year & $\begin{array}{c}\text { Number of galls } \\
\text { per culm }\end{array}$ & $\begin{array}{c}\text { Percentage of galls from which } \\
\text { A. rhopaloides emerged (\%) }\end{array}$ & $\begin{array}{c}\text { Percentage of galls from which } \\
\text { D. aiolomorphi emerged (\%) }\end{array}$ \\
\hline 1999 & $790.4 \pm 729.8 \mathrm{a}$ & $1.5 \pm 1.0 \mathrm{a}$ & $45.6 \pm 5.7 \mathrm{a}$ \\
2000 & $117.9 \pm 72.5 \mathrm{a}$ & $2.0 \pm 2.1 \mathrm{a}$ & $47.7 \pm 18.6 \mathrm{a}$ \\
2001 & $240.0 \pm 321.2 \mathrm{a}$ & $1.1 \pm 1.0 \mathrm{a}$ & $21.5 \pm 13.6 \mathrm{a}$ \\
\hline
\end{tabular}

Mean \pm SD.

Same letters in each column indicate no significant differences $(p>0.05)$.

among the 3 years (number: $F=1.777, \mathrm{df}=2$, $p=0.201 ; \quad \% \mathrm{GM}: \quad F=0.507, \quad \mathrm{df}=2, \quad p=0.612$; \%INQ: $F=0.674, \mathrm{df}=2, p=0.524$ ) (Table 2). The \%INQ tended to be higher than \%GM. The \%INQ ranged from $21.5 \%$ to $45.6 \%$ (Table 2 ).

\section{Spatial distribution pattern on bamboo culms and branches}

Based on the bamboo culms, the indices of spatial distribution, $I_{\delta}$, indicate that bamboo galls were distributed contagiously in 3 years (1999: $I_{\delta}=1.68$, $\chi^{2}=2,695.7, \quad \mathrm{df}=4, \quad p<0.01 ; \quad 2000: \quad I_{\delta}=1.32$, $\chi^{2}=312.3, \quad \mathrm{df}=7, \quad p<0.01 ; \quad 2001: \quad I_{\delta}=3.27$, $\left.\chi^{2}=2,731.5, \mathrm{df}=5, p<0.01\right)$. The bamboo galls from which $D$. aiolomorphi emerged were distributed contagiously on the bamboo culms in 1999 and 2001 (1999: $I_{\delta}=1.70, \chi^{2}=1,250.5, \mathrm{df}=4$, $p<0.01 ; 2000: I_{\delta}=1.04, \chi^{2}=21.6, \mathrm{df}=7, p>0.05$; 2001: $\left.I_{\delta}=2.81, \chi^{2}=805.1, \mathrm{df}=5, p<0.01\right)$.

Based on the bamboo branches, the indices of spatial distribution indicate that bamboo galls were distributed contagiously in 3 years (1999: $I_{\delta}=2.54$, $\chi^{2}=6,343.0, \quad \mathrm{df}=274, \quad p<0.01 ; 2000: I_{\delta}=3.19$, $\chi^{2}=2,530.0, \mathrm{df}=466, \quad p<0.01 ; 2001: I_{\delta}=4.34$, $\left.\chi^{2}=5,208.1, \mathrm{df}=296, p<0.01\right)$. The bamboo galls from which $D$. aiolomorphi emerged were distributed contagiously on the bamboo branches in 3 years $\quad\left(1999: \quad I_{\delta}=2.64, \quad \chi^{2}=3,209.0, \quad \mathrm{df}=274\right.$, $p<0.01 ; \quad 2000: \quad I_{\delta}=3.24, \quad \chi^{2}=1,301.7, \quad \mathrm{df}=466$, $p<0.01 ; 2001: I_{\delta}=5.26, \quad \chi^{2}=2,273.8, \quad \mathrm{df}=397$, $p<0.01)$. These results suggest that the galls and galls from which $D$. aiolomorphi emerged on branches are distributed contagiously.

The indices of spatial distribution, $I_{\delta}$, of galls and galls from which $D$. aiolomorphi emerged tended to be very similar to those of overall galls on both bamboo culms and branches (Fig. 1).

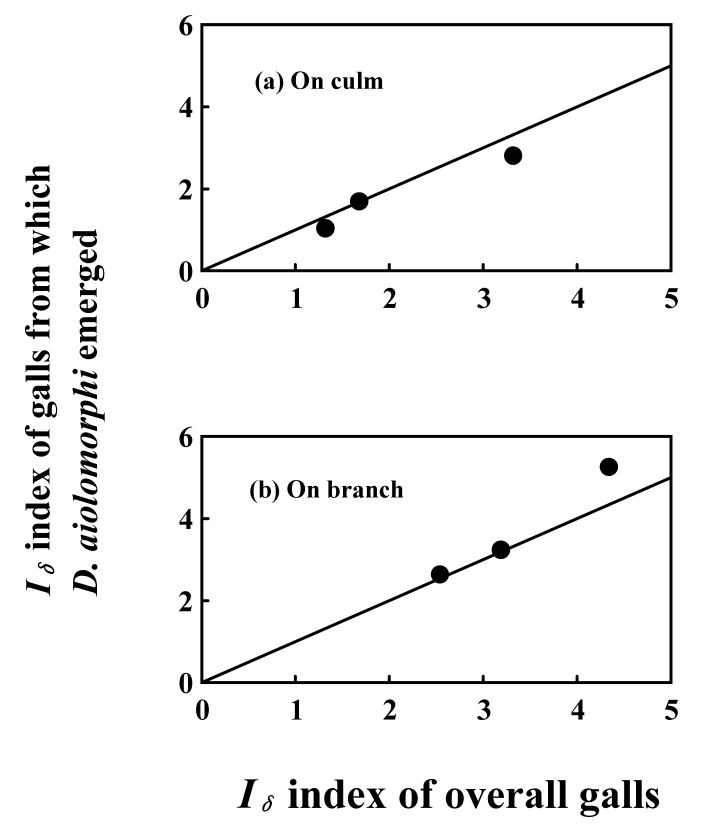

Fig. 1. Relationships between the indices of spatial distribution, $I_{\delta}$, of galls and galls from which $D$. aiolomorphi emerged on bamboo culms (a) and branches (b). Straight lines indicate the relationship of $Y=X$.

\section{Vertical distribution}

There was a significant difference in the mean number of galls per $10-\mathrm{cm}$ branch length among height classes in every year (1999: $F=6.331$, $\mathrm{df}=5,200, p<0.001 ; 2000: F=1.287, \mathrm{df}=5,242$, $p=0.270 ; 2001: F=0.912, \mathrm{df}=5,242, p=0.612$ ) with more galls at middle parts in 1999 and 2000 and at lower parts in 2001 (Fig. 2a). However, there were no significant differences in the \%GM for height classes in each year (1999: $F=1.355$, $\mathrm{df}=5,201, p=0.243 ; 2000: F=2.322, \mathrm{df}=2,238$, $p=0.054 ; 2001: F=1.234, \mathrm{df}=3,191, p=0.295)$ (Fig. 2b). The \%INQ did not differ significantly between height classes in each year (1999: $F=0.526$, $\mathrm{df}=5,201, p=0.756 ; 2000: F=2.435, \mathrm{df}=5,242$, 

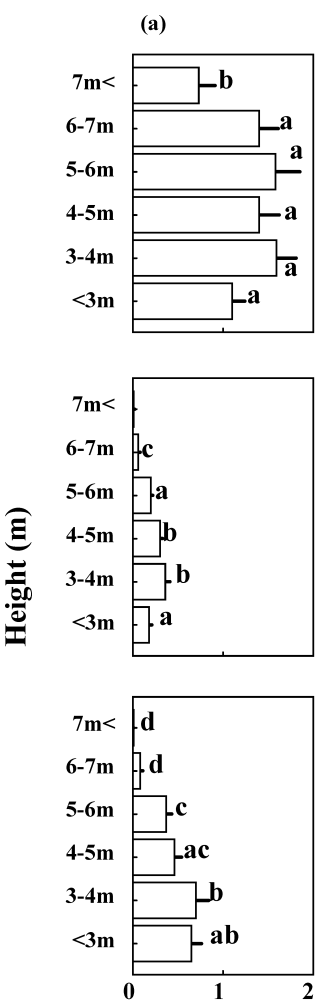

No. galls per $10-\mathrm{cm}$ branch length (b)
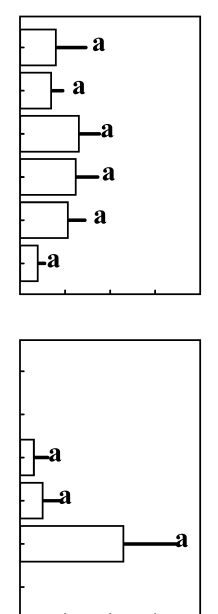

(c)
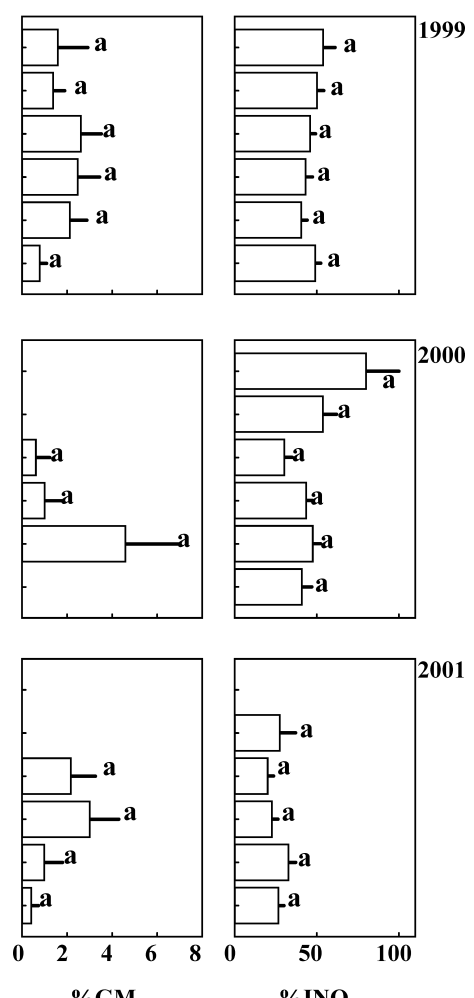

\%GM

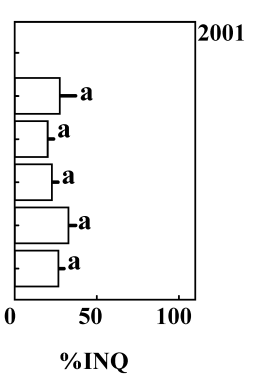

Fig. 2. Mean number of galls per 10-cm branch length (a), and percentages of galls from which A. rhopaloides emerged (\%GM) (b) and galls from which D. aiolomorphi emerged (\%INQ) (c) at each bamboo height class. Horizontal lines indicate + SE. Different letters indicate significant differences $(p<0.05)$.

$p=0.055 ; 2001: \quad F=0.927, \mathrm{df}=5,191, \quad p=0.612)$ (Fig. 2c).

\section{Detection of density dependence}

Significant positive linear correlations were found between gall number and gall number from which D. aiolomorphi emerged in 1999 and 2001 on bamboo culms (Fig. 3). There were no significant differences between the number of galls per $10-\mathrm{cm}$ branch length and \%INQ in each year (1999: $F=0.232$, df=4, $p=0.920 ; 2000: F=0.568$, $\mathrm{df}=1, p=0.452 ; 2001: F=1.001, \mathrm{df}=2, p=0.318)$ (Fig. 4). These results suggest that mortality due to D. aiolomorphi did not occur through gall density dependence on culms and branches.

\section{DISCUSSION}

Shibata (2001) pointed out that phenological
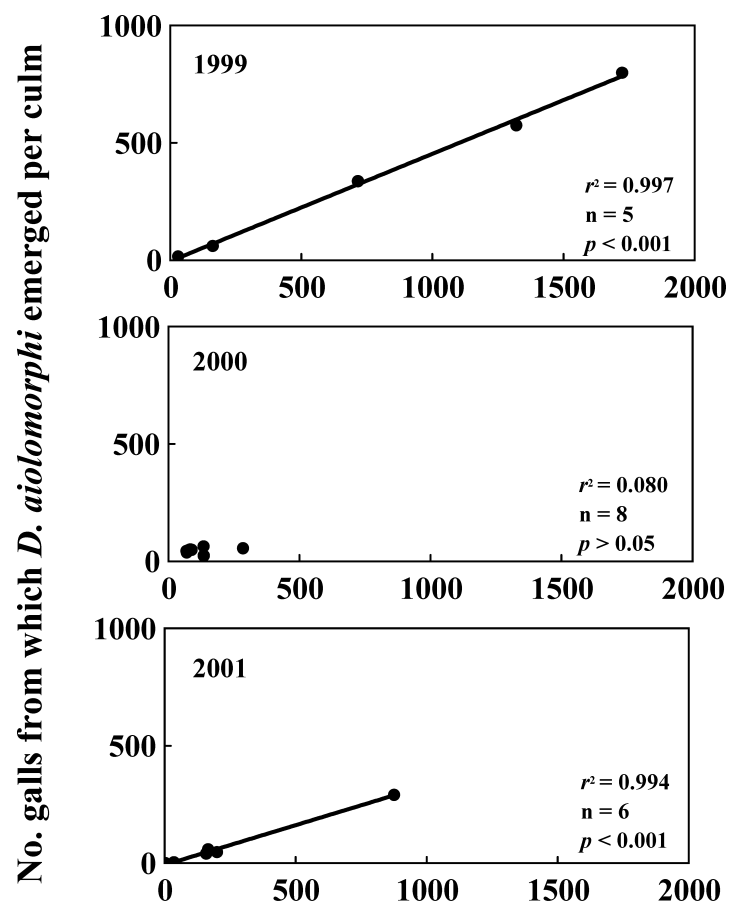

No. galls per culm

Fig. 3. Relationships between the number of galls and the number of galls from which D. aiolomorphi emerged in 3 years.

asynchrony between adult emergence and bud burst as a bottom-up effect may have large effects on the population fluctuation of $A$. rhopaloides. Furthermore, since the percentage of $D$. aiolomorphi emerging from overwintering galls was relatively high during 3 years (Table 2), parasitism of D. aiolomorphi as a top-down force (Shibata, 2006) might be also a main mortality factor of bamboo galls.

Takahashi and Mizuta (1971) showed that when larvae of $A$. rhopaloides and $D$. aiolomorphi live in the same gall in June and July, the latter usurps the gall because of faster growth and harder body surface. The percentage of larvae of D. aiolomorphi in galls from July to March tended to be constant (Shibata and Ito, 2005) and larval development is completed by August of the same year (Takahashi and Mizuta, 1971). These findings suggest that once a larva of $D$. aiolomorphi usurps a gall, the number of $D$. aiolomorphi larvae tends to be stable due to the low parasitism of the facultative hyperparasitoid (Shibata and Ito, 2005), and allowing us to evaluate the density-dependent parasitism of $D$. aiolomorphi by counting the number of galls from 

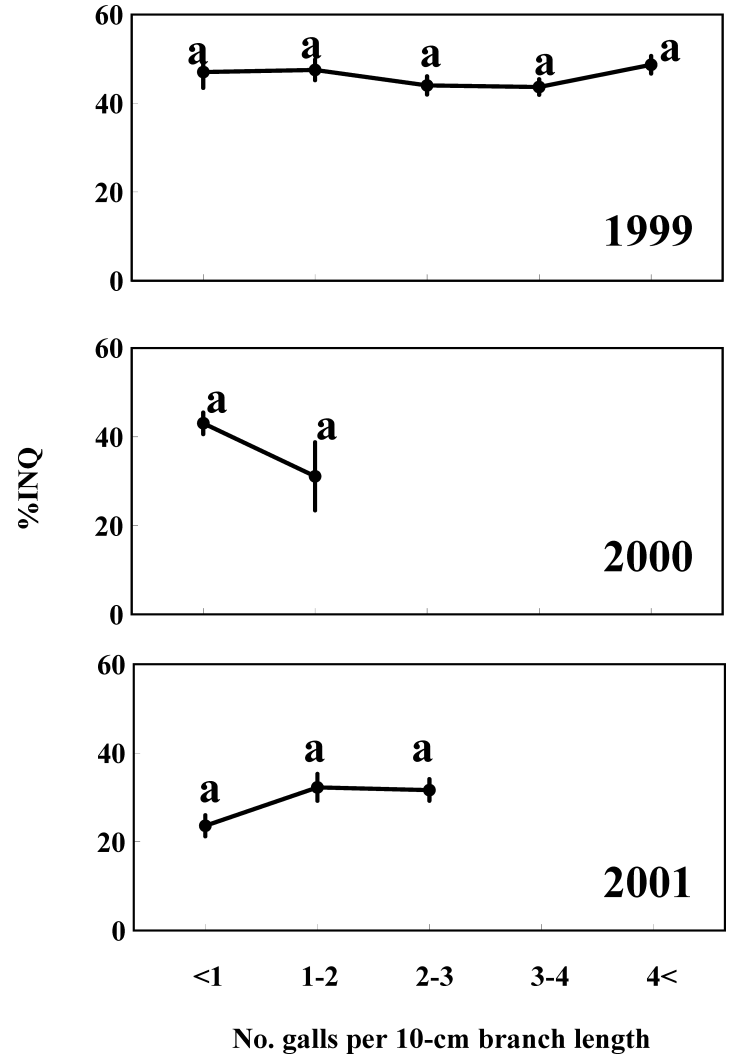

Fig. 4. Percentages of galls from which D. aiolomorphi emerged (\%INQ) in each class of the number of galls per 10$\mathrm{cm}$ branch-length. Vertical lines indicate \pm SE. Different letters indicate significant differences $(p<0.05)$.

which adult $D$. aiolomorphi emerge.

In this study, bamboo galls were distributed contagiously on both bamboo culms and branches. Kuno (1986) noted that the spatial distribution of insects is not usually random, but is often contagious due to oviposition behavior. A. rhopaloides is pro-ovigenic; emerging females have ca. 80 eggs in their ovaries, suggesting that they can oviposit soon after emergence (Shibata, 2002). Consequently, the difference in culm and branch phenology, that is, asynchronism of adult emergence of $A$. rhopaloides and bud-burst of branches where females lay eggs (Shibata, 2003), might affect the contagious distribution pattern of galls (Shibata, 2005). The contagious spatial distribution is also due to the uneven quality of habitats (Kuno, 1986). More bamboo galls are formed on longer branches, so galls are distributed contagiously on branches because longer branches with more buds allow more effective oviposition (Shibata, 2005).

If $D$. aiolomorphi lays eggs on fresh galls ag- gregatively, the index of spatial distribution of galls on culms and branches from which $D$. aiolomorphi emerged should be higher than that of overall galls; bias in the distribution pattern of galls from which D. aiolomorphi emerged might be higher than that of galls. However, there was no clear difference in indices of spatial distribution between galls from which $D$. aiolomorphi emerged and overall galls (Fig. 1), suggesting that D. aiolomorphi does not attack galls aggregatively on particular culms and branches.

The effect of measurement scale for the spatial density-dependent parasitism is important for detecting aggregative responses in parasitoids (Force and Moriarty, 1988; Rothman and Darling, 1990; Lill, 1998). Gall density-dependent mortality of $A$. rhopaloides by $D$. aiolomorphi was not observed on two scales: culms and branches (Figs. 3, 4). Contagious spatial distribution of parasitism is often seen at the behavioral level in which the aggregative response of adult female parasitoids in patches of different host density is examined (Hassell, 1982). Adults of inquilines generally emerge from galls soon after the gall maker and oviposit in freshly initiated galls (Wiebes-Rijks and Shorthouse, 1992). D. aiolomorphi also emerges from galls 15-20 days later than $A$. rhopaloides (Shibata, 2001, 2005). Unlike $A$. rhopaloides, D. aiolomorphi is synovigenic; $D$. aiolomorphi females have no eggs in their ovaries when they emerge but develop eggs continuously as adults age (ca. 20 eggs after 10 days longevity). Consequently, new D. aiolomorphi females cannot lay eggs on freshly initiated galls aggregatively and successively, suggesting that $D$. aiolomorphi attacks regardless of gall density. In addition, the number of galls was different among height classes but \%INQ was not (Fig. 2), suggesting that females of D. aiolomorphi parasitize galls independently of culm height. This result consists with the density-independent parasitism by $D$. aiolomorphi females.

\section{ACKNOWLEDGEMENTS}

I thank K. Kamijo for insect identification, and M. Ito and N. Ikai for invaluable suggestions. Thanks are also due to the members of the Laboratory of Forest Protection, Nagoya University, for their help with the fieldwork. This study was supported in part by a Grant-in-Aid for Scientific Research (No. 11460068) from the Ministry of Education, Culture, Sports, Science and Technology, Japan. 


\section{REFERENCES}

Askew, R. R. (1961) On the biology of the insect inhabitants of oak galls of Cynipidae (Hymenoptera) in Britain. Trans. Soc. British Entomol. 14: 237-268.

Force, D. C. and D. J. Moriarty (1988) Effects of patch scale on density-dependence and species-dependence in two host-parasitoid systems. Oecologia 76: 439-444.

Hails, R. S. and M. J. Crawley (1992) Spatial density dependence in populations of a cynipid gall-former Andricus quercuscalicis. J. Anim. Ecol. 61: 567-583.

Hassell, M. P. (1982) Patterns of parasitism by insect parasitoids in patchy environments. Ecol. Entomol. 7: 365377.

Hassell, M. P., R. M. May, S. W. Pacala and P. L. Chesson (1991) The persistence of host-parasitoid associations in patchy environment. 1. A general criterion. Am. Nat. 138: 568-583.

Kobayashi, F. (1994) Bamboo gall chalcid. In Forest Insects (F. Kobayashi and A. Taketani eds.). Yokendo, Tokyo, pp. 523-524 (in Japanese).

Krebs, C. J. (1998) Ecological Methodology. 2nd ed. Addison Wesley Longman, Menlo Park, California. 620 pp.

Kuno, E. (1986) Research on Animal Populations. 1. Density Estimation Method. Kyoritsu-Shuppan, Tokyo. 114 pp. (in Japanese).

Lill, J. T. (1998) Density-dependent parasitism of the hackberry nipplegall maker (Homoptera: Psyllidae): a multiscale analysis. Environ. Entomol. 27: 657-661.

Morisita, M. (1959) Measuring of the dispersion of individuals and analysis of the distribution patterns. Mem. Fac. Sci., Kyushu Univ., Ser. E (Biol.) 2: 215-235.

Norussis, H. J. (1993) SPSS for Windows, release 6.01. SPSS, Chicago, IL.

Roininen, H., P. W. Price and J. Tahvanainen (1996) Bottomup and top-down influences in the trophic system of a willow, a galling sawfly, parasitoids and inquilines. Oikos 77: 44-50.

Rothman, L. D. and D. C. Darling (1990) Parasitoids of the goldenrod gall moth: effects of scale on spatial density dependence. Oecologia 83: 1-6.

Sanver, D. and B. A. Hawkins (2000) Galls as habitats: the inquiline communities of insect galls. Bas. Appl. Ecol. 1: $3-11$.
Shibata, E. (2001) Synchronization of shoot elongation in the bamboo Phyllostachys heterocycla (Monocotyledoneae: Gramineae) and emergence of the gall maker Aiolomorphus rhopaloides (Hymenoptera: Eurytomidae) and its inquiline Diomorus aiolomorphi (Hymenoptera: Torymidae). Environ. Entomol. 30: 1098-1102.

Shibata, E. (2002) Potential fecundity of the bamboo gall maker, Aiolomorphus rhopaloides (Hymenoptera: Eurytomidae), and its inquiline, Diomorus aiolomorphi (hymenoptera: Torymidae), in relation to gall size and body size. J. For. Res. 7: 117-120.

Shibata, E. (2003) Sampling procedure for density estimation of bamboo galls induced by Aiolomorphus rhopaloides (Hymenoptera: Eurytomidae) in a bamboo stand. J. For. Res. 8: 123-126.

Shibata, E. (2005) Oviposition site preference of bamboo gall maker, Aiolomorphus rhopaloides (Hymenoptera: Eurytomidae), on bamboo in terms of plant-vigor hypothesis. Appl. Entomol. Zool. 40: 631-636.

Shibata, E. (2006) Biology and life history of the bamboo gall maker, Aiolomorphus rhopaloides Walker (Hymenoptera: Eurytomidae). In Galling Arthropods and Their Associates: Ecology and Evolution (J. Yukawa, K. Ozaki, P. W. Price and T. Ohgushi eds.). Springer-Verlag Tokyo, Tokyo, pp. 199-207.

Shibata, E. and M. Ito (2005) Life-history traits in insect inclusions associated with bamboo galls. Insect Sci. 12: $143-150$.

Takahashi, F. and K. Mizuta (1971) Life cycles of a Eurytomid wasp, Aiolomorphous rhopaloides, and three species of wasps parasitic on it. Jpn. J. Appl. Entomol. Zool. 15: 36-43 (in Japanese with English summary).

Wiebes-Rijks, A. A. and J. D. Shorthouse (1992) Ecological relationships of insects inhabiting cynipid galls. In Biology of Insect-Induced Galls (J. D. Shorthouse and O. Rohfritsch eds.). Oxford University Press, New York, pp. 238-257.

Yamamura, K. (1999) Transformation using $(x+0.5)$ to stabilize the variance of populations. Res. Popul. Ecol. 41: 229-234.

Yukawa, J. and H. Masuda (1996) Insect and Mite Galls of Japan in Color. Zenkoku Noson Kyoiku, Tokyo. 826 pp. (in Japanese). 